\title{
Optimal Seismic Design of Steel Plate Shear Walls Using Metaheuristic Algorithms
}

\author{
Ali Kaveh*, Mohammad Farhadmanesh² \\ ${ }^{1}$ Centre of Excellence for Fundamental Studies in Structural Engineering, School of Civil Engineering, Iran University of Science \\ and Technology, Narmak, Tehran-16, Iran \\ 2 School of Civil Engineering, Iran University of Science and Technology, Narmak, Tehran-16, Iran \\ * Corresponding author, e-mail: alikaveh@iust.ac.ir
}

Received: 20 February 2018, Accepted: 27 March 2018, Published online: 19 April 2018

\begin{abstract}
In this paper three well-known metaheuristic algorithms comprising of Colliding Bodies Optimization, Enhanced Colliding Bodies Optimization, and Particle Swarm Optimization are employed for size and performance optimization of steel plate shear wall systems. Low seismic and high seismic optimal designs of these systems are performed according to the provisions of AISC 360 and AISC 341. In one part of the low seismic example, a moment frame and Steel Plate Shear Wall (SPW) strength are compared. Performance optimization of the Special Plate Shear Wall (SPSW) for size optimized system is one of the objectives of the high seismic example. Finally, base shear sensitivity analysis on optimal high seismic design of SPSW and size optimization of a 6-story to a 12-story SPSW are performed to have a comprehensive view on the optimal design of steel plate shear walls.
\end{abstract}

\section{Keywords}

size and performance optimization, steel plate shear wall systems, low seismic and high seismic optimal design, colliding bodies optimization, enhanced colliding bodies optimization

\section{Introduction}

Recently, the number of high-rise residential and commercial buildings is increased considerably and engineers tend to use tall and slender structures. In these buildings, the effects of lateral loads such as wind loads and seismic forces are substantial and special attention is needed for their design. There are different lateral load resisting systems, and the use of steel plate shear walls is one of these systems with high energy dissipation.

A steel plate shear wall is a lateral load resisting system that contains an infill plate attached to the surrounding beams and columns and acts like a cantilever wall in the total height of the building. These walls are subjected to high seismic loads showing high initial stiffness, and behave in a very ductile manner absorbing high amount of energy. The steel shear walls can be employed not only in design of new buildings but also can be utilized for the retrofit of the existing buildings.

In 1980 before fundamental research on this type of steel walls, using the capacity of the steel plate shear walls by preventing from buckling was the design approach of the Japanese and Americans by employing significant number of stiffeners in both directions with thin plates and by using thick plates, respectively (Verma and Maru [1]). Both solutions had economic problems due to the cost of the material and construction. Nevertheless, quite a few experiments proved that non-stiffened thin steel plate shear walls benefit a high ductility and strength after the buckling in the compression direction (Sabelli and Bruneau [2]).

SPSW buckling strength in pressure depends on slenderness of the plate - ratio of the length to thickness and width to thickness. These ratios are usually high for conventional buildings, and moreover the erection of these walls is not quite flat due to manufacturing errors. Consequently, buckling strength of the SPSWs in compression is very low. The generated principal compressive stresses are much more than the compressive strength in the plate when loads are applied to these walls; hence, the plate buckles in compressive directions and forms fold lines and tensile stresses that are perpendicular to the compressive directions. Lateral loads are transferred by these principal diagonal tension stresses through the web plate, and this behavior is defined as post-buckling tension field action (Sabelli and Bruneau [2]). For the first time, post-buckling properties such as stiffness 
and strength of the steel plate shear walls were recognized by Thorburn et al. [3] and then Timler and Kulak [4] studied it by experimental analysis. Sánchez-Olivares and Espín [5] included the semi-rigid behavior of the connections. A frequency based design optimization of plates was performed by Armand [6].

Design optimization of frame structures in terms of size and topology is performed by An and Huang [7]; stability based design by Suleman and Sedaghati [8]; reliability based design is by Kogiso et al. [9]; and displacement based design by Missoum and Gurdal [10]. The variables of the frame structures are defined as discrete for optimization process in this study similar to others such as Arora [11], Beckers [12], Blachowski and Gutkowski [13] that proposed handling methods for these kind of problems. Kaveh and Zakian [14] used charge system search and harmony search to optimize steel frames under seismic loads utilizing time history analysis and dynamic static analysis. Kaveh et al. [15] considered connection types in addition to the element sections for seismic design optimization of steel moment frames. Many other recently developed metaheuristic algorithms for optimal design of frame structures can be found in Kaveh [16].

The remainder of the paper is organized as follows. Section 2 provides some of the modeling methods for steel plate shear walls. In section 3, a brief compilation of the design requirements for the SPW and SPSW systems subjected to low and high seismic loads is presented in order to use as the design constraints of the section 5; then, section 4 includes a brief explanation of the CBO and ECBO algorithms. Finally, optimization examples - low and high seismic design, a comparison between moment frame and SPW in optimal form, performance optimization of the SPSW, base shear sensitivity analysis on optimal high seismic design of SPSW, as well as size optimization of the 6- to 12-story SPSW - are included in section 5. The final section concludes the present study.

\section{Different modelling techniques for steel plate shear walls}

There are various methods to simulate a Steel Plate Shear Wall system in order to determine the stiffness and strength of the system. Strip model, partial strip model, pratt truss model (Thorburn et al. [3]), truss model (Topkaya and Atasoy [17]), multi-angle model (Rezai et al. [18]), modified strip model (Shishkin et al. [19]), cyclic strip model (Elgaaly et al. [20]) and orthotropic membrane model (Sabelli and Bruneau [2]) can be utilized to measure

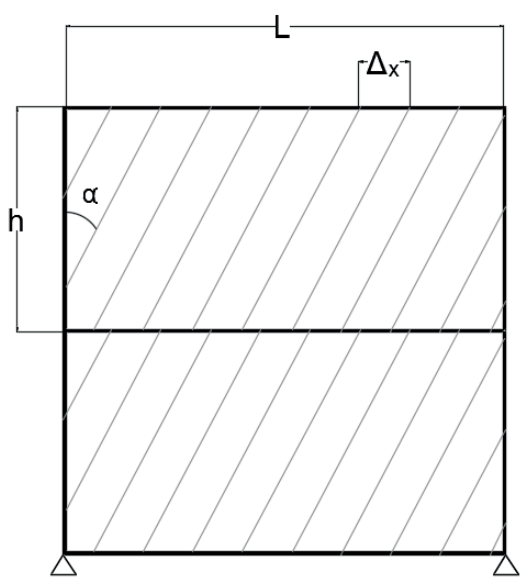

Fig. 1 Schematic of a typical strip model

the stiffness and strength of a Steel Plate Shear Wall system. In this paper, the strip model - which is employed for analyzing purposes - is presented in detail.

\subsection{Strip model}

In this method, infill plate in each panel is replaced with a set of parallel steel bar members which can resist only tension stresses and are inclined direction as shown in Fig. 1. It is recommended that a minimum of 10 strips to be employed to have a sufficient accuracy in simulating the effects of the resulted forces on elements of the frame Sabelli and Bruneau [2]. The horizontal distance $\left(\Delta_{x}\right)$ between two consecutive strips on the beam for $m$ strips is calculated as:

$\Delta_{x}=1 / m[L+h \cdot \tan (\alpha)]$

where $L$ is the width of the panel, $h$ is the height of the panels and $\alpha$ is the angle between the direction of the strips and the vertical direction.

The cross-sectional area of an equivalent strip considering the steel plate thickness $\left(t_{w}\right)$ is calculated as follows:

$A_{s}=\frac{[L \cdot \cos (\alpha)+h \cdot \sin (\alpha)] t_{w}}{m}$

In this paper, the strip model is employed for modeling the steel plate shear wall in low seismic loads case and for the performance based optimization subjected to high seismic loads. This method is quite reliable in comparison to other methods since all of the forces resulted in steel plate are simulated and transferred to the boundaries in a realistic manner. The reliability of this method has been investigated with experimental tests. Additionally, due to substituting the plate with a sufficient bar elements, the interaction of the internal forces is quite precise. 
Simplicity of using this method in optimal design process is another reason for its suitability. After all, the cross sectional area of the bar elements must be changed during the process of optimization, and bar inclinations must also be set to the angle of web yielding. While according to the AISC recommendation [21], designers can use a fix angle for bar elements if it does not change more than 5 degrees. Furthermore, since all the structures in this paper are considered to be symmetric, there is no need for the opposite direction (right to left) to be checked.As mentioned, seeking higher wind velocity in offshore regions has led us toward utilizing frame substructures, by which larger wind turbines can be placed in harsher environments of such regions; thus, this research is conducted in order to explore the optimal design of jacket supporting structures. Note that only the optimal design of this part of the offshore wind turbine structure is investigated in this study.

\section{Design requirements}

Steel structures, depending on the buildings site, are divided into two categories, namely low seismic and high seismic. The differences in these categories are on the ductility of the steel plate. Low seismic design requirements are for limited ductility of the web plate and high seismic design requirements are for high ductility of the web plate that needs special provisions of AISC 341 [22].

In low seismic design mode, boundary elements (columns defined as vertical boundary elements and beams defined as horizontal boundary elements) should remain elastic, while formation of the plastic hinges in two ends of horizontal boundary elements is allowed in high seismic design mode.

\subsection{Requirements for low seismic design}

In this section, design constraints for low seismic mode are determined for structures that are in sites with response modification factor equal or less than 3. High seismic design should also fulfill these requirements. As AISC 360 [21] does not include the requirements for steel plate shear walls, some general constraints from AISC 341 [22] are used in low seismic design.

There are two types of analysis approach in low seismic state: using internal forces resulted directly from analysis, or utilizing the forces calculated with assumption of the uniform distribution of the average tension stress in the steel plate. In this work, the former approach is applied. It should be noted that the beam and column elements must be remained in elastic area for both low and high seismicity zones, and plates may or may not reach the yielding area.
Design constraints are as follows:

1) Allowable shear strength:

$\phi V_{n}=(\phi) 0.42 F_{y} L_{c f} t_{w} \sin (2 \alpha)$

Angle of web yielding:

$\tan ^{4} \alpha=\frac{1+\frac{t_{w} \cdot L}{2 A_{c}}}{1+t_{w} \cdot h\left[\frac{1}{A_{b}}+\frac{h^{3}}{360 I_{c} \cdot L}\right]}$

where $F_{y}$ is the infill panel yield stress, $L_{c f}$ is the clear distance between vertical boundary elements flanges, $t_{w}$ is the thickness of the infill plate, $\phi$ is the resistance factor ( $\phi=0.9$ ), $L$ is the bay width, $h$ is the story height, $I_{c}$ is the moment of inertia of the vertical boundary element, $A_{c}$ and and $A_{b}$ are the cross-sectional area of the vertical boundary element and horizontal boundary element, respectively.

2) Stiffness constraint of the vertical boundary elements:

$I_{c} \geq 0.00307 \frac{t_{w} h^{4}}{L}$

3) Stiffness constraint of the horizontal boundary elements:

$I_{b} \geq 0.003 \frac{\left(\Delta t_{w}\right) L^{4}}{h}$

where $\Delta t_{w}$ is the difference in web plate thicknesses above and below of the beam.

4) Strength constraints of the boundary elements:

if $\frac{P_{r}}{P_{c}}<0.2: \frac{P_{r}}{2 P_{c}}+\frac{M_{r}}{M_{c}} \leq 1.0$

if $\frac{P_{r}}{P_{c}} \geq 0.2: \frac{P_{r}}{P_{c}}+\left(\frac{8}{9}\right) \frac{M_{r}}{M_{c}} \leq 1.0$

where $P_{r}$ and $P_{c}$ are the required and available axial - compressive and tensile - strength, respectively. $M_{r}$ and $M_{c}$ are the required and available flexural strength, respectively. Nominal strength of elements for both compression and tension have been calculated under AISC 360 [21] supervisions.

for compression elements:

$$
\begin{aligned}
& P_{c}=\phi_{c} P_{n(c o n p r e s s i o n)}, \quad \phi_{c}=0.9, P_{n(\text { compresion })}=A_{g} F_{c r} \\
& \begin{cases}F_{c r}=\left(0.658^{\lambda_{c}^{2}}\right) F_{y}, & \text { for } \lambda_{c} \leq 1.5 \\
F_{c r}=\left(\frac{0.877}{\lambda_{c}^{2}}\right) F_{y}, & \text { for } \lambda_{c}>1.5\end{cases}
\end{aligned}
$$


$\lambda_{c}=\frac{k l}{r \pi} \sqrt{\frac{F_{y}}{E}}$

where $A_{g}$ is the cross-sectional area of a member, and $k$ is the effective length factor that is calculated by:

$k=\sqrt{\frac{1.6 G_{A} G_{B}+4.0\left(G_{A}+G_{B}\right)+7.5}{G_{A}+G_{B}+7.5}}$

where $G_{A}$ and $G_{B}$ are stiffness ratios of columns and girders at the two end joints $A$ and $B$ of the the column section, respectively.

for tension elements:

$P_{c}=\phi_{t} P_{n(\text { tension })}, \quad \phi_{t}=0.9, P_{n(\text { tension })}=A_{g} F_{y}$

5) The inter-story displacement constraint:

$\Delta_{i}=\left(\delta_{e(i)}-\delta_{e(i-1)}\right) \frac{C_{d}}{I_{e} h_{s i}} \leq 0.02$

where $\delta_{e(i)}$ is the deflection at level $i, C_{d}$ is the deflection amplification factor, $I_{e}$ is the importance factor, and $h_{s i}$ is the story height below level $i$.

\subsection{Requirements for high seismic design}

In this section, additional design constraints for high seismic mode are determined for structures that are in sites with response modification factor greater than 3 .

A combined plastic and linear analysis which is recommended by AISC 341 [22] in commentary section due to high ductility of the system is used to determine internal forces in the boundary elements in order to design based on the capacity of the SPSW system. In this analysis, beams and columns must remain in elastic area under the forces that are resulted from the yielding of the plates.

It is preferred that the failure in web plates happen prior to failure in boundary elements since the web plates are not designed to carry the gravity loads.

Two types of mechanism shown in Fig. 2 have been considered for collapse mechanism of the SPSW system according to Berman and Bruneau researches: complete uniform yielding mechanism in height of the structure and local mechanism in one story named soft story mechanism. To ensure former mechanism is dominated in design of this system it is essential to avoid using unnecessary extra amount of thickness in web plates of the steel plate panels. Since inappropriate relative displacement happens if unnecessary extra thicknesses in any story in comparison with the upper or lower stories, which leads to a big relative change in the stiffness across different stories, is

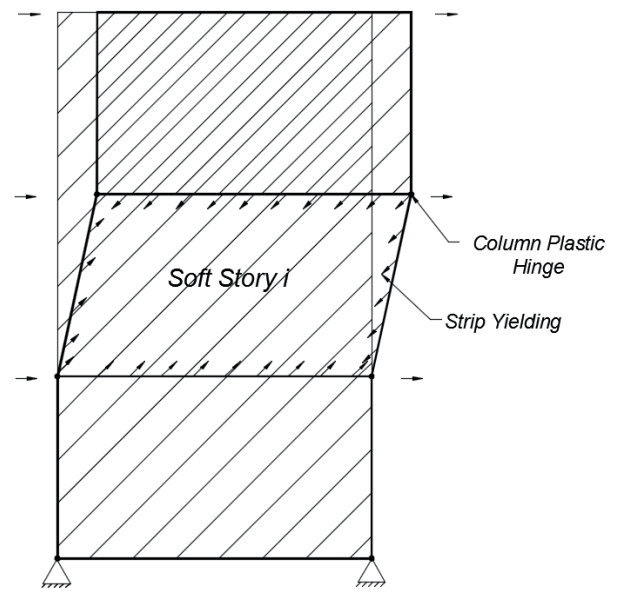

Fig. 2 Schematic of a SPSW collapse mechanisms

employed in the web plates, and as a result it leads to undesirable soft story mechanism. Also, this can be a compelling reason of designing this system in optimal form.

In soft story mechanism, plastic hinges form in two ends of the columns and just in one of the stories. It is undesirable collapse mechanism since only one story reaches to its ultimate capacity. In the other hand, using the capacity of the all stories in uniform yielding mechanism due to formation of plastic hinges at two ends of beams makes it desirable collapse mechanism. Some design requirements in this section lead to the formation of this desirable collapse mechanism such as Strong-Column Weak-Beam constraint in beam-to-column connections.

Design constraints are as follows:

1) Strong-Column Weak-Beam:

$\frac{\sum M_{p c}^{*}}{\sum M_{p b}}>1.0$

$M_{p c}^{*}=\left(F_{y}-P_{u} / P_{y}\right) Z$

$M_{p b}=M_{p r}+V_{u} s_{h}$

$s_{h}=1 / 2\left(d_{b}+d_{c}\right)$

$M_{p r}=1.1 R_{y} F_{y} Z_{R B S}$

where $\sum M_{p c}^{*}$ is the sum of column plastic moment strengths at a connection (reduced due to axial force), $\sum M_{p b}^{*}$ is the sum of beam plastic moment strengths at a connection, $P_{u}$ is the axial force in columns, $P_{y}$ is equal to $A_{g}, F_{y}, d_{b}$ and $d_{c}$ are the beam and column depth, $V_{u}$ is the shear force in the beam at the location of the formed hinge, $M_{p r}$ is the beam plastic moment strength in the absence of axial force, $R_{y}$ is 


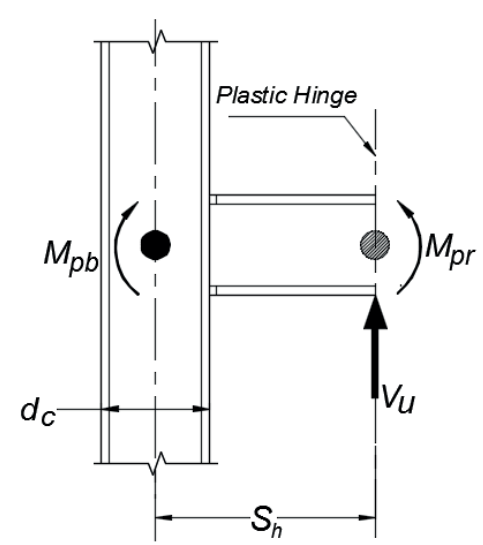

Fig. 3 Forces at column centerline resulted from beam plastic hinge

ratio of the expected yield stress to the specified minimum yield stress $\left(F_{y}\right), Z_{R B S}$ is the plastic section modulus of the reduced beam section $\left(=2 / 3 Z_{x}\right)$. All the forces and dimensions are illustrated in Fig. 3.

2) Compactness constraint:

For wings of the W-shaped sections:

$$
\frac{b_{f}}{2 t_{f}} \quad 0.3 \sqrt{\frac{E}{F_{y}}}
$$

For webs of the W-shaped sections:

$$
\begin{aligned}
& \text { for } C_{a} \leq \frac{1}{8}: \frac{h}{t_{w}} \leq 3.14 \sqrt{\frac{E}{F_{y}}}\left[1-1.54 C_{a}\right] \\
& \text { for } C_{a}>\frac{1}{8}: \quad \frac{h}{t_{w}} \leq 1.12 \sqrt{\frac{E}{F_{y}}}\left[2.23-C_{a}\right] \\
& C_{a}=\frac{P_{u}}{\phi_{b} P_{y}}
\end{aligned}
$$

where $C_{a}$ is the axial force ratio, and $E$ is the modulus of elasticity of the steel.

\section{The utilized optimization algorithms}

Colliding bodies optimization algorithm introduced by Kaveh and Mahdavi [24] is based on the idea of collision between two bodies in one dimension. In this method, CBs (colliding bodies) collide to each other until they reach an optimum location, and physics law is used to calculate the corresponding quantities in the $\mathrm{CBO}$ algorithm. First, the steps of the $\mathrm{CBO}$ algorithm are described; then, an enhanced colliding bodies optimization procedure which is proposed by Kaveh and Ilchi Ghazaan [25] is elaborated. For brevity, PSO is not explained here and the interested reader may refer to Kaveh [16] for complete explanation.

\subsection{Colliding Bodies Optimization}

In order to have a good definition of the algorithm, physical laws used in the process of the algorithm are described.

\subsubsection{Collision laws}

When two bodies collide together, the velocity of the bodies before and after the collision are derived based on the laws of momentum and energy. In an isolated system for elastic collision, the total kinetic energy and the total momentum of the bodies are conserved; this can be expressed as follows:

$$
\begin{aligned}
& m_{1} v_{1}+m_{2} v_{2}=m_{1} v_{1}^{\prime}+m_{2} v_{2}^{\prime} \\
& \frac{1}{2} m_{1} v_{1}^{2}+\frac{1}{2} m_{2} v_{2}^{2}=\frac{1}{2} m_{1} v_{1}^{\prime 2}+\frac{1}{2} m_{2} v_{2}^{\prime 2}+Q
\end{aligned}
$$

where $v_{1}$ and $v_{2}$ are the velocity of the bodies before collision, $v_{1}^{\prime}$ and $v_{2}^{\prime}$ are the velocity of the bodies after collision, $m_{1}$ and $m_{2}$ are the mass of pair colliding bodies, and $Q$ is the loss of energy as a consequence of the collision.

Finally, the velocity of the bodies after collision can be obtained by using Eqs. (24) and (25):

$$
\begin{aligned}
& v_{1}^{\prime}=\frac{\left(m_{1}-\varepsilon m_{2}\right) v_{1}+\left(m_{2}+\varepsilon m_{2}\right) v_{2}}{m_{1}+m_{2}} \\
& v_{2}^{\prime}=\frac{\left(m_{2}-\varepsilon m_{1}\right) v_{2}+\left(m_{1}+\varepsilon m_{1}\right) v_{1}}{m_{1}+m_{2}}
\end{aligned}
$$

where $\varepsilon$ is the coefficient of restitution which can be defined as follows:

$\varepsilon=\frac{\left|v_{2}^{\prime}-v_{1}^{\prime}\right|}{\left|v_{2}-v_{1}\right|}$

Two types of collision can be considered:

A perfectly elastic collision: $Q=0 \& \varepsilon=1$

An inelastic collision: $Q \neq 0 \& \varepsilon \leq 1$

\subsubsection{The $\mathrm{CBO}$ algorithm}

In $\mathrm{CBO}$, each $\mathrm{CB}$ is a solution vector which is included a number of variables. Bodies are divided into two equal groups named as stationary and moving bodies. The moving bodies move to stationary bodies in order to the collision to happen. Improvement of the position of moving bodies and alteration of stationary bodies positions are two main purposes of this classification in bodies. The main steps of the $\mathrm{CBO}$ can be described as follows:

Level 1: Initialization

Step 1: A random initialization for $\mathrm{CBs}$ first positions is employed in the search space: 
$x_{i}^{0}=x_{\text {min }}+\operatorname{rand}\left(x_{\text {max }}-x_{\text {min }}\right), \quad i=1,2, \ldots, n$

where $x_{i}^{0}$ is the initial value of the ith $\mathrm{CB}$ vector, $x_{\min }$ and $x_{\max }$ are the allowable value boundary of the variables vectors, rand is a decimal number in the interval [0,1], and $n$ is total population of the CBs. It should be noted that the numbers will be rounded since the variables are discrete.

Level 2: Search

Step 1: Evaluation the value of the objective function for each $\mathrm{CB}$ and sort them from low to high.

Step 2: Defining groups of the stationary (good agents) and moving bodies as pair colliding bodies in virtual impact. Stationary CBs are the ones in the lower half of CBs after the sort of objective function, and similarly moving CBs are in the upper half of CBs.

Step 3: Calculation the values of the mass and velocity of the CBs before the collision by Eqs. (30), (31), and (32):

$m_{k}=\frac{\frac{1}{f i t(k)}}{\sum_{i=1}^{n} \frac{1}{f i t(i)}}, \quad k=1,2, \ldots, n$

The velocity of stationary bodies before the collision:

$v_{i}=0, \quad i=1, \ldots, \frac{n}{2}$

The velocity of moving bodies before the collision:

$v_{i}=x_{i}-x_{i-\frac{n}{2}}, \quad i=\frac{n}{2}+1, \ldots, n$

where $x_{i}$ and $v_{i-\frac{n}{2}}$ are the position of the $i$ th $\mathrm{CB}$ and its pair in previous group, respectively.

Step 4: Calculation the value of velocity of CBs after the collision:

The velocity of stationary bodies after the collision:

$$
v_{i}^{\prime}=\frac{\left(m_{i+\frac{n}{2}}+\varepsilon m_{i+\frac{n}{2}}\right) v_{i+\frac{n}{2}}}{m_{i}+m_{i+\frac{n}{2}}}, \quad i=1, \ldots, \frac{n}{2}
$$

where $v_{i+\frac{n}{2}}$ and $v_{1}^{\prime}$ are the velocity of the ith stationary bodies before and after the collision, $m_{i}$ and $v_{i+\frac{n}{2}}$ are the mass of the $i$ th $\mathrm{CB}$ and its pair in next group, respectively.

The velocity of moving bodies after the collision:

$v_{i}^{\prime}=\frac{\left(m_{i}-\varepsilon m_{i-\frac{n}{2}}\right) v_{i}}{m_{i}+m_{i-\frac{n}{2}}}, \quad i=\frac{n}{2}+1, \ldots, n$ where $v_{1}$ and $v_{1}^{\prime}$ are the velocity of the $i$ th moving bodies before and after the collision, $m_{i}$ and $v_{i-\frac{n}{2}}$ are the mass of the ith $\mathrm{CB}$ and its pair in previous group, respectively.

Also, $\varepsilon$ can be defined as:

$\varepsilon=1-\frac{\text { iter }}{\text { iter }_{\max }}$

where iter $_{\text {max }}$ is maximum number of iteration and iter is the number of actual iteration.

Step 5: Updating the CBs positions:

The updated position of stationary bodies:

$x_{i}^{\text {new }}=x_{i}+\operatorname{rand} \circ v_{i}^{\prime}, \quad i=1, \ldots, \frac{n}{2}$

where $x_{i}^{\text {new }}$ and $x_{i}$ are the new position and old position of the ith stationary bodies.

the updated position of moving bodies:

$x_{i}^{\text {new }}=x_{i-\frac{n}{2}}+\operatorname{rand} \circ v_{i}^{\prime}, \quad i=\frac{n}{2}+1, \ldots, n$

where $x_{i}^{\text {new }}$ and $v_{i-\frac{n}{2}}$ are the new position of the ith moving bodies and old position of its pair in previous group, respectively.

Level 3: Continue previous level steps until a terminating criterion is satisfied.

\subsection{Enhanced Colliding Bodies Optimization}

In ECBO algorithm, a number of best $\mathrm{CBs}$ from previous iterations are replaced by the current worst $\mathrm{CBs}$ by a parameter named colliding memory (CM); as a result, the convergence rate increases (Kaveh A, Ilchi Ghazaan M. [24]). In addition, another parameter named pro is utilized in order to escape from local optimal answers. The main steps of the ECBO can be described as follows:

Level 1: Initialization

Step 1: A random initialization for CBs first positions is employed in the search space (use Eq. (29))

\section{Level 2: Search}

Step 1: Evaluation the value of the objective function for each $\mathrm{CB}$ in order to calculate the value of its masses (use Eq. (30))

Step 2: Use colliding memory (CM) to substitute a number of old best CBs by the current worst CBs.

Step 3: Sorting the objective function in an ascending order and defining groups of the stationary (good agents) and moving bodies as pairs of colliding bodies.

Step 4: Calculate the velocity of the colliding bodies (moving and stationary bodies) before and after the collision (use Eqs. (31), (32), (33), and (34)) 
Step 5: Update the CBs positions (use Eqs. (36) and (37))

Step 6: Use the pro to escape from local optimal answers, and to this end, a number between interval $(0,1)$ is chosen randomly and compared with the value of the pro, which is selected between interval $(0,1)$; if this random number is lower than pro, one random variable of the colliding body is selected again among available search space randomly. This action does for all of the CBs.

Level 3: Continue previous level steps until a terminating criterion is satisfied.

\section{Structural optimization}

\subsection{Optimization formulation}

In this work, the objective functions are defined as minimization of the weight and standard deviation (standard deviation is used for performance based design optimization of SPSW exclusively and has no other role in this work) of the story drifts in SPSW system while stiffness, strength, and displacement constraints should be satisfied. The solution formulae of these problems are determined as follows:

$$
\text { Find }\{X\}=\left[x_{1}, x_{2}, \ldots, x_{n g}\right]
$$

To minimize

$W(\{X\})=\sum_{i=1}^{n m} \rho_{i} V_{i}$

$\operatorname{Std}(\{X\})=\sqrt{\frac{1}{N} \sum_{i=1}^{N}\left(d r i f t_{i}-\overline{d r i f t}\right)^{2}}$

Subjected to: $\left\{\begin{array}{l}g_{j}(\{X\}) \leq 0, \quad j=1,2, \ldots, n c \\ x_{i \min } \leq x_{i} \leq x_{i \max }\end{array}\right.$

where $\{X\}$ is the vector of design variables, $n g$ is the number of design variables, $W(\{X\})$ is the weight of structure, $\mathrm{nm}$ is the number of the elements in the structure, $\rho_{i}$ and $V_{i}$ are the material density and volume of the ith member, respectively; $\operatorname{Std}(\{X\})$ presents the standard deviation of the story drifts, $N$ is the number of story, and are the story drift in the ith story drift $t_{i}$ and $\overline{d r i f t}$ average value of the story drifts, respectively; $x_{i \text { min }}$ and $x_{i \max }$ are the lower bound and upper bound of the design variables, $g_{j}(\{X\})$ represents design constraints, and $n c$ is the number of design constraints.

The penalty approach is employed to handle the constraints of numerical examples. Penalty function multiplied by objective function constitutes a new objective function (the fitness function) that is used in optimization algorithms. The formulation of the penalty function is expressed as follows:

$$
\operatorname{Penalty}(\{X\})=\left(1+\varepsilon_{1} \cdot v\right)^{\varepsilon_{2}} \quad v=\sum_{j=1}^{n c} \max \left[0, g_{j}(\{X\})\right](40)
$$

where $v$ is the total violations of the constraints, the $\varepsilon_{1}$ constant is considered because of exploration rate of the search space which is set to unity, and the $\varepsilon_{2}$ constant is considered because of exploitation rate of the search space which is changed from 1.5 to 6 during the optimization process.

\subsection{Numerical examples}

\subsubsection{Low Seismic Design Example}

Optimal design of a 2D frame inhibited by steel plate shear walls shown in Fig. 4 which is part of a building in a zone of low seismicity in Chicago (with response modification factor equal 3) is considered to verify the presented algorithms and to investigate optimal form of the new structural system (SPW). This example is proposed in AISC Design Guide number 20 (Sabelli and Bruneau 2007) (Steel Plate Shear Walls) and is used in this study to have an authentic numerical example in terms of structural geometry, loading, as well as design constraints for the steel plate shear wall system. Total weight of the building which is assumed located a site in Chicago is 20700 kips (92078 $\mathrm{kN})$; ASTM A36 $\left(F_{y}=36 \mathrm{ksi}\left(248211 \mathrm{kN} / \mathrm{m}^{2}\right), F_{u}=58 \mathrm{ksi}\right.$ $\left.\left(399895 \mathrm{kN} / \mathrm{m}^{2}\right)\right)$ and ASTM A992 $\left(F_{y}=50 \mathrm{ksi}(344737 \mathrm{kN} /\right.$ $\left.\left.\mathrm{m}^{2}\right), F_{u}=65 \mathrm{ksi}\left(448159 \mathrm{kN} / \mathrm{m}^{2}\right)\right)$ are used for web plate material and boundary elements material, respectively; the material has a modulus of elasticity equal to $E=29000 \mathrm{ksi}$ $\left(199947961 \mathrm{kN} / \mathrm{m}^{2}\right)$. Well-known W shaped sections introduced in AISC instructions are the sections bank for frame members, and 13 thicknesses $(0.0625,0.0673,0.0747$, $0.1046,0.125,0.1345,0.1875,0.250,0.3125,0.375$, $0.4375,0.500$, and 0.625 inch or $0.15875,0.17094,0.18973$, $0.26568,0.3175,0.34163,0.47625,0.635,0.79375,0.9525$, $1.11125,1.27$, and 1.5875 centimeter) which is determined in AISC Design Guide number 20 example are used for web plate thicknesses in frame panels.
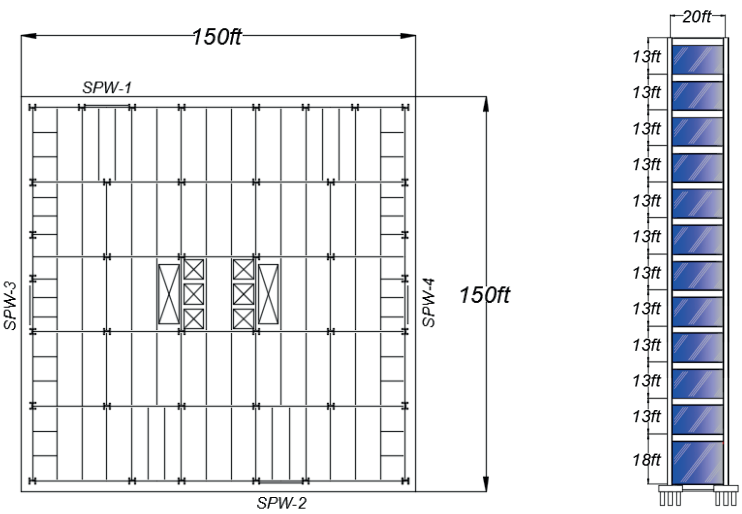

Fig. 4 Schematic of a typical floor plan and SPW elevation 
Table 1 Earthquake load acting on the 9-story SPW

\begin{tabular}{lcc} 
& \multicolumn{3}{c}{ Forces and Shears in each SPW } \\
Level & Frame Force $(\mathrm{kN})$ & Frame Shear $(\mathrm{kN})$ \\
\hline Roof & 467 & 467 \\
$9^{\text {th }}$ Floor & 362 & 827 \\
$8^{\text {th }}$ Floor & 315 & 1143 \\
$7^{\text {th }}$ Floor & 268 & 1410 \\
$6^{\text {th }}$ Floor & 222 & 1632 \\
$5^{\text {th }}$ Floor & 176 & 1810 \\
$4^{\text {th }}$ Floor & 132 & 1943 \\
$3^{\text {rd }}$ Floor & 89 & 2032 \\
$2^{\text {nd }}$ Floor & 49 & 2081 \\
\hline
\end{tabular}

Beam-to-column connections are rigid according to AISC 341 [22] requirements for Steel Plate Shear Wall systems, and a strut beam is embedded in the middle of first story panel. A second order $\mathrm{P}-\Delta$ analysis is employed in order to affect the secondary effects of axial loads in frame elements. SAP 2000 version 18 is utilized for simulation and analysis purposes (a nonlinear analysis). It is worthy to mention that beams and columns should remain in elastic area and plates can reach the yielding area. Also, the optimization process is coded in MATLAB 2015a.

Base shear in this building is distributed vertically based on Eqs. (41) and (42) (the exponent $\mathrm{k}$ is 1.12 for this building design), ASCE [23]. Table 1 determines calculated earthquake loads in all levels of the frame for each SPW.

$$
\begin{aligned}
& F_{x}=C_{v x} V \\
& C_{v x}=\frac{w_{x} h_{x}^{k}}{\sum_{i=1}^{n-s t o r y} w_{i} h_{i}^{k}}
\end{aligned}
$$

Low seismic optimum design of a 9-story steel plate shear wall and a comparison with optimum design of a 9-story moment frame in the same condition, are the objectives of this section. Columns in each story are categorized in one group, and there are no category for beams since their moment inertia (stiffness) constraint may require heavy sections in some stories, which are not required in other stories.

In $\mathrm{CBO}, \mathrm{ECBO}$, and PSO, the population of $n=30$ agents is used for the design problems. In ECBO, the size of colliding memory is taken as 5 , and the pro parameter increases linearly from 0.3 to 0.5 during the optimization process.

First column in Table 2 belongs to AISC Design Guide number 20 Low Seismic example. Optimization of this example is performed in order to have a lighter structure and define an authentic benchmark example for steel plate

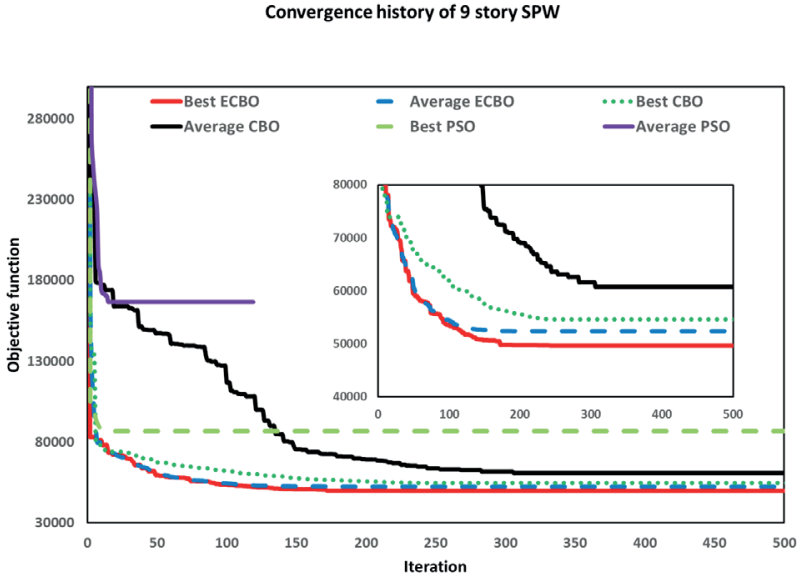

Fig. 5 Convergence curves of the 9-story SPW; best and average CBO, ECBO and PSO

shear wall system. Accordingly, second column in Table 2 is the optimal structure found by ECBO that is 38 percent lighter than AISC Design Guide example; in this design, like Design Guide example only W14 sections are used for vertical boundary elements (VBEs); additionally, stiffness constraint for horizontal boundary elements (HBEs) is eliminated in order to have more categorized beams sections. In rest of the columns in Table 2, there is no extra consideration, and thus all $\mathrm{W}$ shaped sections for VBEs and stiffness constraint for HBEs are considered in design procedure. Third, fourth, and fifth columns in Table 2 are for optimal design obtained by $\mathrm{ECBO}, \mathrm{CBO}$, and $\mathrm{PSO}$, respectively. The best weight is for $\mathrm{ECBO}$ algorithm that has 43 percent lighter weight in comparison with AISC Design Guide example, and also it contains the most use of steel plates in comparison with other algorithm answers. As it is seen in Fig. 5, both the best answer and the best average answer are obtained by ECBO which has a faster convergence rate too. This shows the high ability of the ECBO algorithm for finding the optimum answer of such a complex structure like steel plate shear wall with more complicated constraint than simple, conventional structure. It is noteworthy to say that the best answer obtained by ECBO shown in Fig. 5 is near to its average answers, which elucidates the magnificent performance of this algorithm for structural problems.

Fig. 5 shows that PSO is not appropriate for this complex structural problem since it is severely trapped in local optimal answer. The main reason is that there is no strategy to escape from local optimal answers, and in addition, inclination of the particles for converging to the best answer is too much in comparison to the other mentioned algorithms. 
Table 2 Comparative results of the 9-story SPW and result of the moment frame

\begin{tabular}{|c|c|c|c|c|c|c|c|}
\hline & \multirow[b]{4}{*}{ Level } & \multicolumn{6}{|c|}{ LOW SEISMIC } \\
\hline & & \multicolumn{5}{|c|}{ SPW } & \multirow[t]{2}{*}{ Moment frame } \\
\hline & & \multirow{2}{*}{$\begin{array}{l}\text { AISC design } \\
\text { example }\end{array}$} & \multicolumn{4}{|c|}{ Optimal design } & \\
\hline & & & ECBO* & ECBO & $\mathrm{CBO}$ & PSO & ECBO \\
\hline \multirow{10}{*}{$\begin{array}{l}\text { Beam sections } \\
\text { (Strut) }\end{array}$} & Roof & W27X94 & W12X26 & W30X99 & W30X99 & W36X182 & W24X55 \\
\hline & $9^{\text {th }}$ Floor & W24X84 & W6X9 & $\mathrm{W} 14 \mathrm{X} 22$ & W14X22 & W30X99 & W27X84 \\
\hline & $8^{\text {th }}$ Floor & W24X84 & $\mathrm{W} 12 \mathrm{X} 26$ & W27X84 & W30X90 & W27X84 & W30X116 \\
\hline & $7^{\text {th }}$ Floor & W24X84 & $\mathrm{W} 16 \times 26$ & W24X55 & W24X55 & W33X141 & W36X135 \\
\hline & $6^{\text {th }}$ Floor & W24X84 & $\mathrm{W} 12 \mathrm{X} 26$ & $\mathrm{~W} 18 \mathrm{X} 40$ & W21X44 & W44X248 & W40X149 \\
\hline & $5^{\text {th }}$ Floor & W24X84 & $\mathrm{W} 12 \mathrm{X} 26$ & W18X35 & W21X44 & W27X84 & W40X149 \\
\hline & $4^{\text {th }}$ Floor & W24X84 & $\mathrm{W} 12 \mathrm{X} 26$ & W30X90 & W30X90 & W33X130 & W44X198 \\
\hline & $3^{\text {rd }}$ Floor & W24X84 & W12X26 & W16X31 & W16X26 & W44X224 & W44X198 \\
\hline & $2^{\text {nd }}$ Floor & W24X84 & W30X99 & $\mathrm{W} 16 \times 26$ & W30X99 & W44X224 & W24X76 \\
\hline & $1^{\text {st }}$ Floor & W10X45 & $\mathrm{W} 14 \mathrm{X} 22$ & $\mathrm{~W} 14 \mathrm{X} 22$ & $\mathrm{~W} 14 \mathrm{X} 22$ & $\mathrm{~W} 14 \mathrm{X} 22$ & W40X167 \\
\hline \multirow{9}{*}{ Column sections } & $9^{\text {th }}$ Floor & W14X132 & W14X48 & $\mathrm{W} 18 \mathrm{X} 40$ & W21X50 & W30X90 & W21X50 \\
\hline & $8^{\text {th }}$ Floor & W14X132 & W14X53 & W16X45 & W21X57 & W27X94 & W27X84 \\
\hline & $7^{\text {th }}$ Floor & W14X233 & W14X74 & W24X68 & W24X68 & W27X114 & W30X108 \\
\hline & $6^{\text {th }}$ Floor & W14X233 & W14X99 & W18X86 & W30X90 & W27X114 & W30X132 \\
\hline & $5^{\text {th }}$ Floor & W14X233 & W14X99 & W27X114 & W24X104 & W36X160 & W36X160 \\
\hline & $4^{\text {th }}$ Floor & W14X233 & W14X132 & W14X120 & W21X147 & W24X207 & W44X198 \\
\hline & $3^{\text {rd }}$ Floor & W14X370 & W14X159 & W27X146 & W27X161 & W36X210 & W40X215 \\
\hline & $2^{\text {nd }}$ Floor & W14X370 & W14X176 & W27X178 & W40X199 & W44X285 & W36X230 \\
\hline & $1^{\text {st }}$ Floor & W14X370 & W14X370 & W36X260 & W40X297 & W40X297 & W40X328 \\
\hline \multirow{9}{*}{$\mathrm{tw}(\mathrm{cm})$} & $9^{\text {th }}$ Floor & 0.15875 & 0.15875 & 0.15875 & 0.15875 & 0.189738 & \\
\hline & $8^{\text {th }}$ Floor & 0.15875 & 0.170942 & 0.15875 & 0.15875 & 0.34163 & \\
\hline & $7^{\text {th }}$ Floor & 0.265684 & 0.265684 & 0.265684 & 0.265684 & 0.34163 & \\
\hline & $6^{\text {th }}$ Floor & 0.265684 & 0.3175 & 0.3175 & 0.3175 & 0.47625 & \\
\hline & $5^{\text {th }}$ Floor & 0.3175 & 0.3175 & 0.34163 & 0.34163 & 0.635 & \\
\hline & $4^{\text {th }}$ Floor & 0.34163 & 0.47625 & 0.34163 & 0.34163 & 0.635 & \\
\hline & $3^{\text {rd }}$ Floor & 0.47625 & 0.47625 & 0.475488 & 0.47625 & 0.635 & \\
\hline & $2^{\text {nd }}$ Floor & 0.47625 & 0.47625 & 0.47625 & 0.47625 & 0.9525 & \\
\hline & $1^{\text {st }}$ Floor & 0.47625 & 0.79375 & 0.47625 & 0.635 & 1.5875 & \\
\hline Weight (N) & & 392371.4 & 241997.05 & 220903.6 & 242910.7 & 384967.3 & 278866.57 \\
\hline Average weight (N) & & & 248581.75 & 233126 & 270301.1 & 741036.8 & 288130.88 \\
\hline No. of analyses & & & 19800 & 7200 & 7260 & 510 & 8490 \\
\hline \multicolumn{8}{|c|}{ *just W14 setions are used for columns (does not include required HBE stiffness) } \\
\hline wall/column & & & $37.50 \%$ & $34.60 \%$ & $31.80 \%$ & $41.20 \%$ & \\
\hline wall/structure & & & $24.30 \%$ & $21.00 \%$ & $19.50 \%$ & $20.90 \%$ & \\
\hline
\end{tabular}

All constraints diagrams for optimum answer obtained by ECBO are set to the ratio of existing value to the allowable value of force, stiffness, as well as displacement which are explained in design requirements section. Fig. 6 depicts the correspondence between strength constraint for combined compression and flexure and stiffness constraints for the VBEs and HBEs, respectively; labels 1 to 9 belong to columns and labels 10 to 19 belong to beams - number 10 is the strut. It is shown that strength is the dominant constraint for columns; however, stiffness requirement for beams in $3^{\text {rd }}, 5^{\text {th }}, 6^{\text {th }}$, and $9^{\text {th }}$ story exceeds the required strength. Finally, Fig. 7 illustrates the shear force and nominal shear strength in web plates that are very close together, which means the structure reaches almost its full capacity. Drift to its allowable value ratio of the optimum answer is also demonstrated in Fig. 8. 


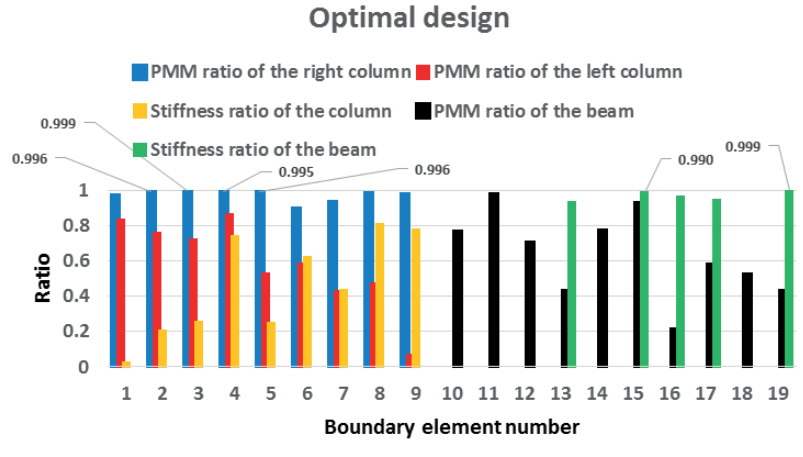

Fig. 6 Strength and stiffness constraints for the 9-story SPW

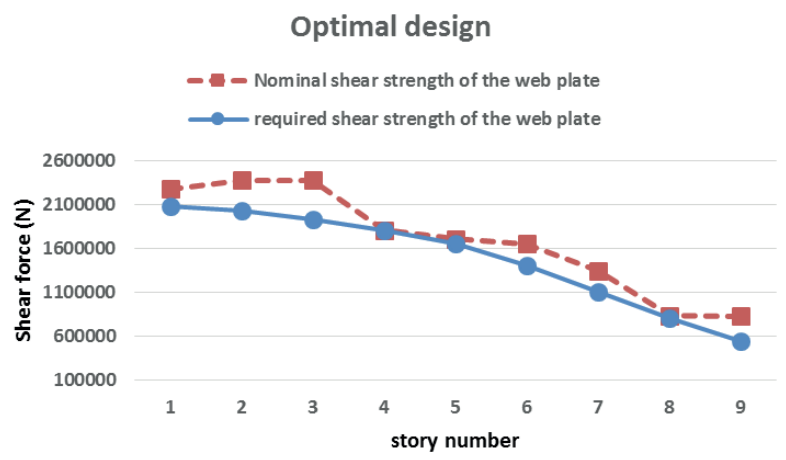

Fig. 7 Strength constraint for the 9-story SPW

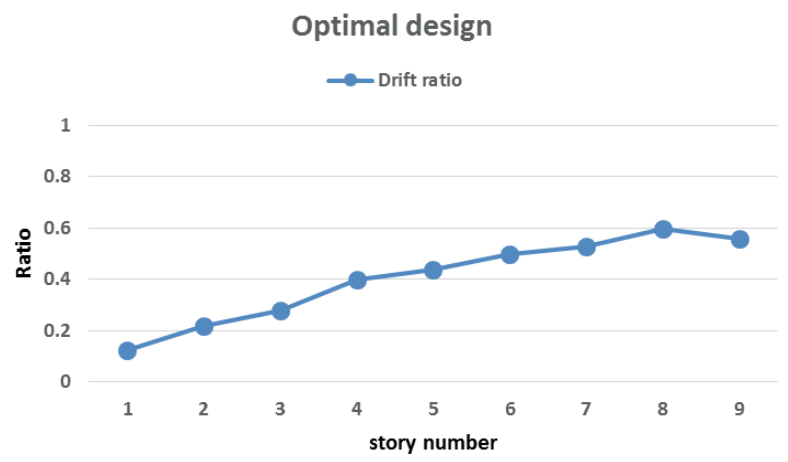

Fig. 8 Displacement constraint for the 9-story SPW

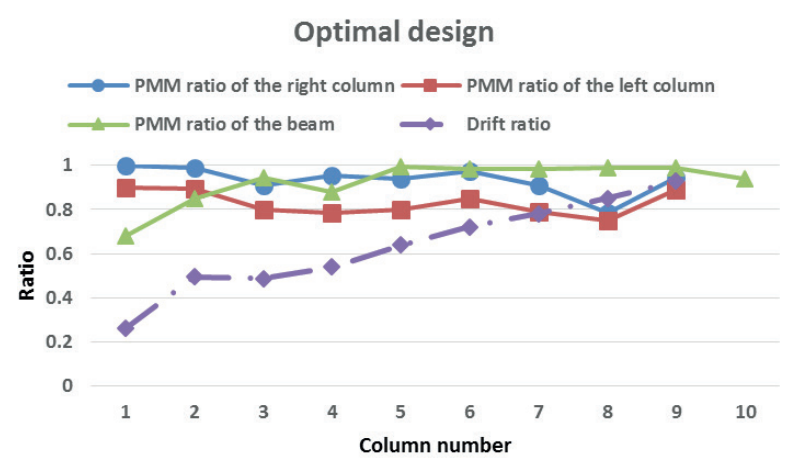

Fig. 9 Strength and displacement constraints for the moment frame

\section{Comparison between moment frame and SPSW system:}

Last column in Table 2 demonstrates optimal design of the moment frame which is similar to the 9-story SPW. The optimization process in this case is performed only
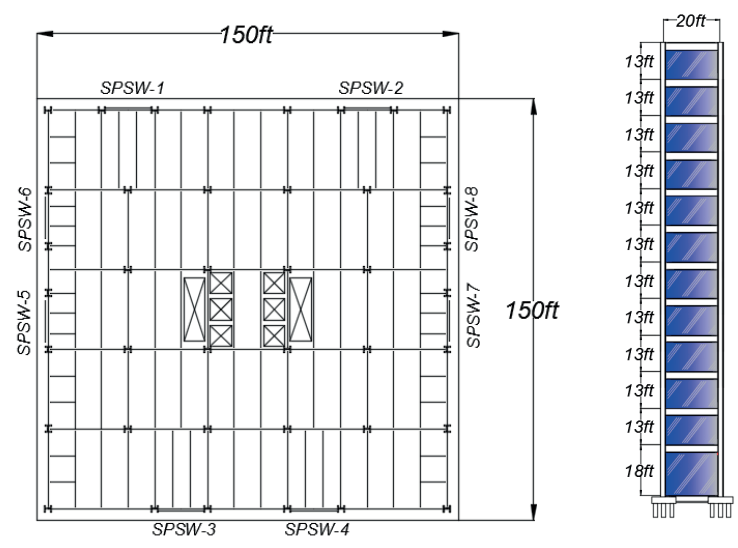

Fig. 10 Schematic of a typical floor plan and SPSW elevation

by ECBO algorithm, in that comparison of the structural system is the main goal in this section, and furthermore ECBO has the best convergence in aforementioned algorithms. Although all the available capacity of the structure is nearly utilized in optimal moment frame based on Fig. 9, weight of its optimum answer is 25 percent heavier than optimum answer of SPW system. This illustrates the fact that using thin steel plates in panels of a one bay frame improves its durability.

\subsubsection{High Seismic Design Example}

Optimal design of a 2D frame inhibited by special steel plate shear walls presented in Fig. 10 which is part of a building in a zone of high seismicity in San Francisco (with response modification factor equal 7) with application of the ductile detail requirements is considered to verify the mentioned algorithms and to investigate optimal form of the new structural system (SPSW). Data banks are similar to low seismic section.

Unlike low seismic example, there is no strut beam in the first story panel; in contrast, a beam on the foundation is embedded for inhibiting the first story web plate since in high ductility application all web plates need to be strictly braced. All of the optimization and analysis processes, using Combined Plastic and Linear Analysis Approach, are coded in MATLAB platform. The lateral unbraced length for each beam is taken as the entire length of the beam for in-plane slenderness calculations and one-third of the span length for the out-of-plane slenderness calculations. Also, the out-of-plane effective length factors of the members are equal to 1 , and the in-plane effective length factor of the members is conservatively specified unity for a frame with side-sway inhibited. All columns are considered non-braced in their length. SAP 2000 version 18 is utilized for simulation and analysis in order to find the best 
Table 3 Earthquake load acting on the 9-story SPSW

\begin{tabular}{lcc}
\hline \multicolumn{3}{c}{ Forces and Shears in Each SPSW } \\
Level & Frame Force $(\mathrm{kN})$ & Frame Shear $(\mathrm{kN})$ \\
\hline Roof & 876 & 876 \\
$9^{\text {th }}$ Floor & 676 & 1552 \\
$8^{\text {th }}$ Floor & 591 & 2144 \\
$7^{\text {th }}$ Floor & 502 & 2646 \\
$6^{\text {th }}$ Floor & 416 & 3065 \\
$5^{\text {th }}$ Floor & 329 & 3394 \\
$4^{\text {th }}$ Floor & 246 & 3638 \\
$3^{\text {rd }}$ Floor & 167 & 3803 \\
$2^{\text {nd }}$ Floor & 92 & 3896 \\
\hline
\end{tabular}

configuration of the uniform drift in high seismic optimal design. Table 3 determines calculated earthquake loads in all levels of the frame for each SPSW.

High seismic optimum design of a 9-story special steel plate shear wall for minimum weight and obtaining a uniform stance for relative displacement of the stories in achieved optimum answer are this section objectives.

In $\mathrm{CBO}, \mathrm{ECBO}$, and $\mathrm{PSO}$, the population of $n=50$ agents is used for the design problems. In ECBO, the size of colliding memory is taken as 10 , and the parameter pro increases linearly from 0.3 to 0.5 during the optimization process.

First column in Table 4 belongs to AISC Design Guide number 20 High Seismic example. Second column in Table 4 is the optimal structure found by ECBO that is 30 percent lighter than AISC Design Guide example; in this design, like Design Guide example only W14 sections are used for vertical boundary elements (VBEs). In rest of the columns in Table 4, all W shaped sections for VBEs can be assigned. Third and fourth columns in Table 4 are for optimal design obtained by $\mathrm{ECBO}$ and $\mathrm{CBO}$, respectively. The best weight is for ECBO algorithm that has 42 percent lighter weight in comparison with AISC Design Guide example, and also it contains steel plates more than the optimal design obtained by CBO. Both the best answer and the best average answer - illustrated in Fig. 11 - are obtained by ECBO which has a faster convergence rate too. This proves the high ability of ECBO in finding the optimal answer for a complex structure (SPSW) with even more complicated constraint than SPW systems. Like low seismic section, the best answer obtained by ECBO and its average answers are close together, which elucidates that performance of ECBO algorithm is quite perfect for SPSW design problems, same as it was for SPW system.

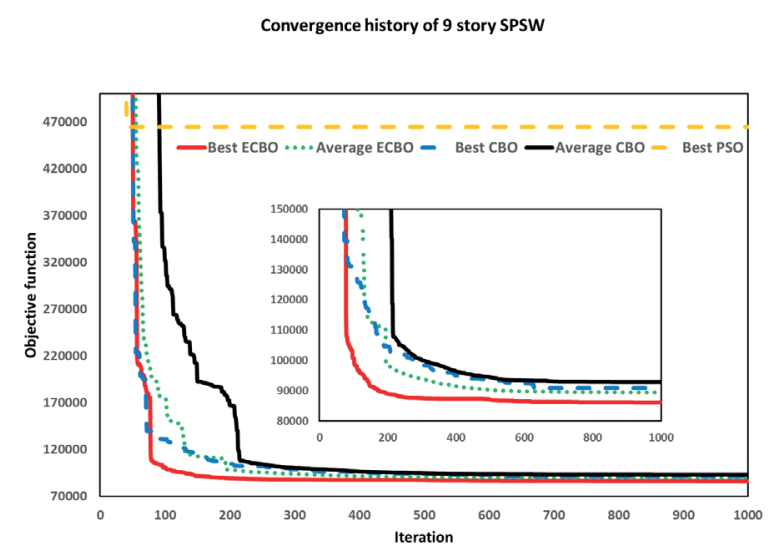

Fig. 11 Convergence curves of the 9-story SPSW; best and average $\mathrm{CBO}, \mathrm{ECBO}$ and PSO

Optimal design

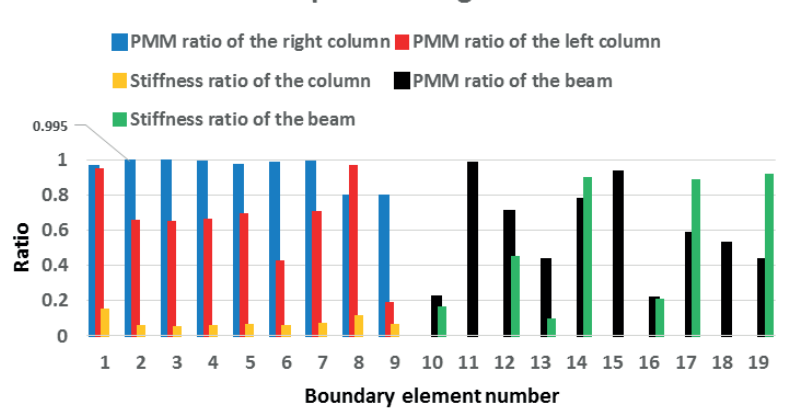

Fig. 12 Strength and stiffness constraints for the 9-story SPSW

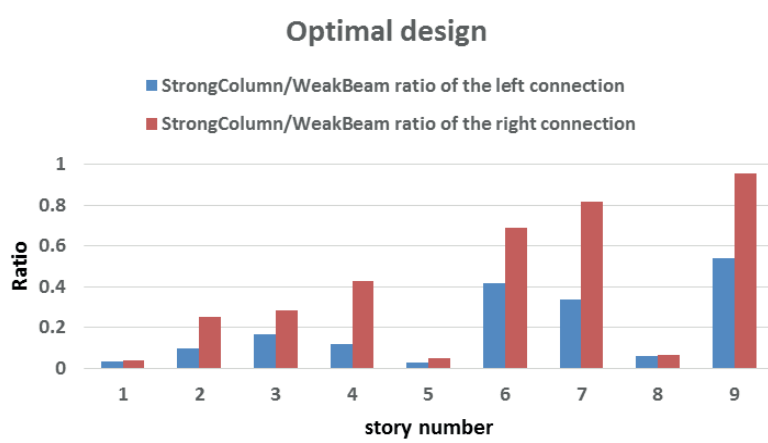

Fig. 13 Strong-Column Weak-Beam constraint for the 9-story SPSW

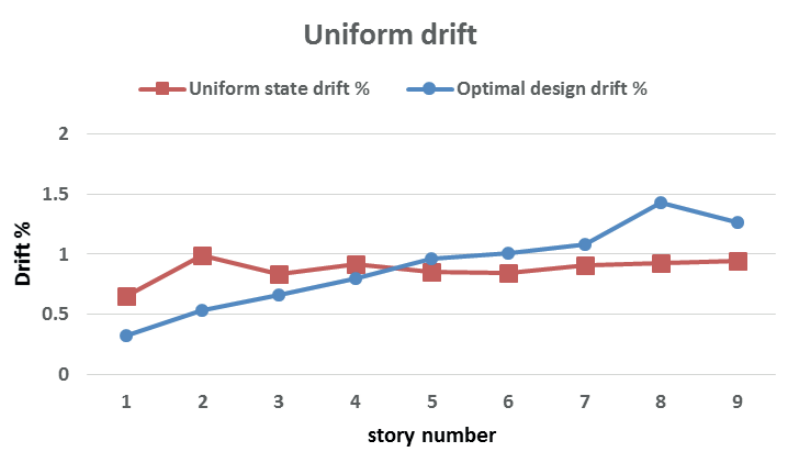

Fig. 14 Comparison of the drift for the 9-story SPSW between uniform state and optimal design 
Table 4 Comparative results of the 9-story SPSW

\begin{tabular}{|c|c|c|c|c|c|c|}
\hline & \multirow[b]{4}{*}{ Level } & \multicolumn{5}{|c|}{ HIGH SEISMIC } \\
\hline & & \multicolumn{5}{|c|}{ SPSW } \\
\hline & & \multicolumn{4}{|c|}{ Optimal design } & \multirow{2}{*}{$\begin{array}{c}\text { Uniform drift state } \\
\text { ECBO }\end{array}$} \\
\hline & & AISC design example & ECBO* & ECBO & $\mathrm{CBO}$ & \\
\hline \multirow{10}{*}{ Beam sections } & Roof & W30X108 & W30X108 & W24X76 & W12X111 & W24X76 \\
\hline & $9^{\text {th }}$ Floor & W27X94 & W18X40 & W14X22 & W12X19 & W14X22 \\
\hline & $8^{\text {th }}$ Floor & W27X94 & W30X90 & W30X99 & W33X130 & W30X99 \\
\hline & $7^{\text {th }}$ Floor & W27X94 & W21X44 & W36X135 & W18X40 & W36X135 \\
\hline & $6^{\text {th }}$ Floor & W30X108 & W18X35 & W16X36 & W27X84 & W16X36 \\
\hline & $5^{\text {th }}$ Floor & W27X94 & W21X50 & W27X84 & W24X55 & W27X84 \\
\hline & $4^{\text {th }}$ Floor & W30X116 & W21X44 & W30X90 & W40X149 & W30X90 \\
\hline & $3^{\text {rd }}$ Floor & W27X94 & W30X90 & W27X84 & W24X55 & W27X84 \\
\hline & $2^{\text {nd }}$ Floor & W27X94 & W24X68 & W21X57 & W30X99 & W21X57 \\
\hline & $1^{\text {st }}$ Floor & W30X108 & W30X90 & W44X198 & W44X198 & W44X198 \\
\hline \multirow{9}{*}{ Column sections } & $9^{\text {th }}$ Floor & W14X283 & W14X283 & W30X99 & W30X124 & W30X99 \\
\hline & $8^{\text {th }}$ Floor & W14X283 & W14X120 & W24X76 & W30X99 & W24X76 \\
\hline & $7^{\text {th }}$ Floor & W14X283 & W14X257 & W36X160 & W40X215 & W36X160 \\
\hline & $6^{\text {th }}$ Floor & W14X398 & W14X233 & W40X215 & W30X173 & W40X215 \\
\hline & $5^{\text {th }}$ Floor & W14X398 & W14X257 & W40X192 & W33X241 & W40X192 \\
\hline & $4^{\text {th }}$ Floor & W14X665 & W14X311 & W40X268 & W40X268 & W40X268 \\
\hline & $3^{\text {rd }}$ Floor & W14X665 & W14X342 & W40X324 & W33X387 & W40X324 \\
\hline & $2^{\text {nd }}$ Floor & W14X665 & W14X500 & W33X387 & W33X354 & W33X387 \\
\hline & $1^{\text {st }}$ Floor & W14X665 & W14X605 & W33X515 & W30X527 & W33X515 \\
\hline \multirow{9}{*}{ tw $(\mathrm{cm})$} & $9^{\text {th }}$ Floor & 0.170942 & 0.170942 & 0.0762 & 0.0762 & 1.524 \\
\hline & $8^{\text {th }}$ Floor & 0.265684 & 0.189738 & 0.0762 & 0.0762 & 1.4478 \\
\hline & $7^{\text {th }}$ Floor & 0.3175 & 0.3175 & 0.2159 & 0.2794 & 0.9652 \\
\hline & $6^{\text {th }}$ Floor & 0.34163 & 0.3175 & 0.2794 & 0.2794 & 0.5588 \\
\hline & $5^{\text {th }}$ Floor & 0.47625 & 0.3175 & 0.2794 & 0.2794 & 1.0414 \\
\hline & $4^{\text {th }}$ Floor & 0.47625 & 0.34163 & 0.381 & 0.3048 & 0.1524 \\
\hline & $3^{\text {rd }}$ Floor & 0.635 & 0.34163 & 0.3937 & 0.3556 & 0.4445 \\
\hline & $2^{\text {nd }}$ Floor & 0.635 & 0.47625 & 0.45085 & 0.3683 & 0.1016 \\
\hline & $1^{\text {st }}$ Floor & 0.635 & 0.47625 & 0.45085 & 0.4826 & 0.0762 \\
\hline Weight (N) & & 670203.76 & 464039.81 & 383467.8 & 404445.7 & 434811.88 \\
\hline Average weight (N) & & & 472793.91 & 398205.2 & 411998.3 & \\
\hline No. of analyses & & & 113429.65 & 204173.4 & 168409.7 & \\
\hline \multicolumn{7}{|c|}{ *just W14 setions are used for columns } \\
\hline wall/column & & & $12.70 \%$ & $12.80 \%$ & $11.60 \%$ & \\
\hline wall/structure & & & $9.90 \%$ & $9.40 \%$ & $8.60 \%$ & \\
\hline
\end{tabular}

In Fig. 11, it is demonstrated that PSO is obviously an impotent algorithm to converge to optimum answers for this complex structural problems since it is severely trapped in local optimal answer.

Fig. 12 indicates that strength constraint is dominant in VBEs for high seismic optimum design too and similarly the stiffness requirement for beams exceeds the required strength in some stories $\left(5^{\text {th }}, 6^{\text {th }}\right.$, and $10^{\text {th }}$ story); labels 1 to 9 belong to columns and labels 10 to 19 correspond to beams - number 10 is the beam that is lied on the foundation. Strong-Column Weak-Beam is the last constraint that is applied to prevent the soft story collapse mechanism; Fig. 13 shows that this constraint does not govern in none of the connections because the optimal design of the SPSW system provides a design mode which tends to collapse in uniform yielding mechanism. 
Table 5 Comparative results of the 9-story SPSW subjected to different base shears

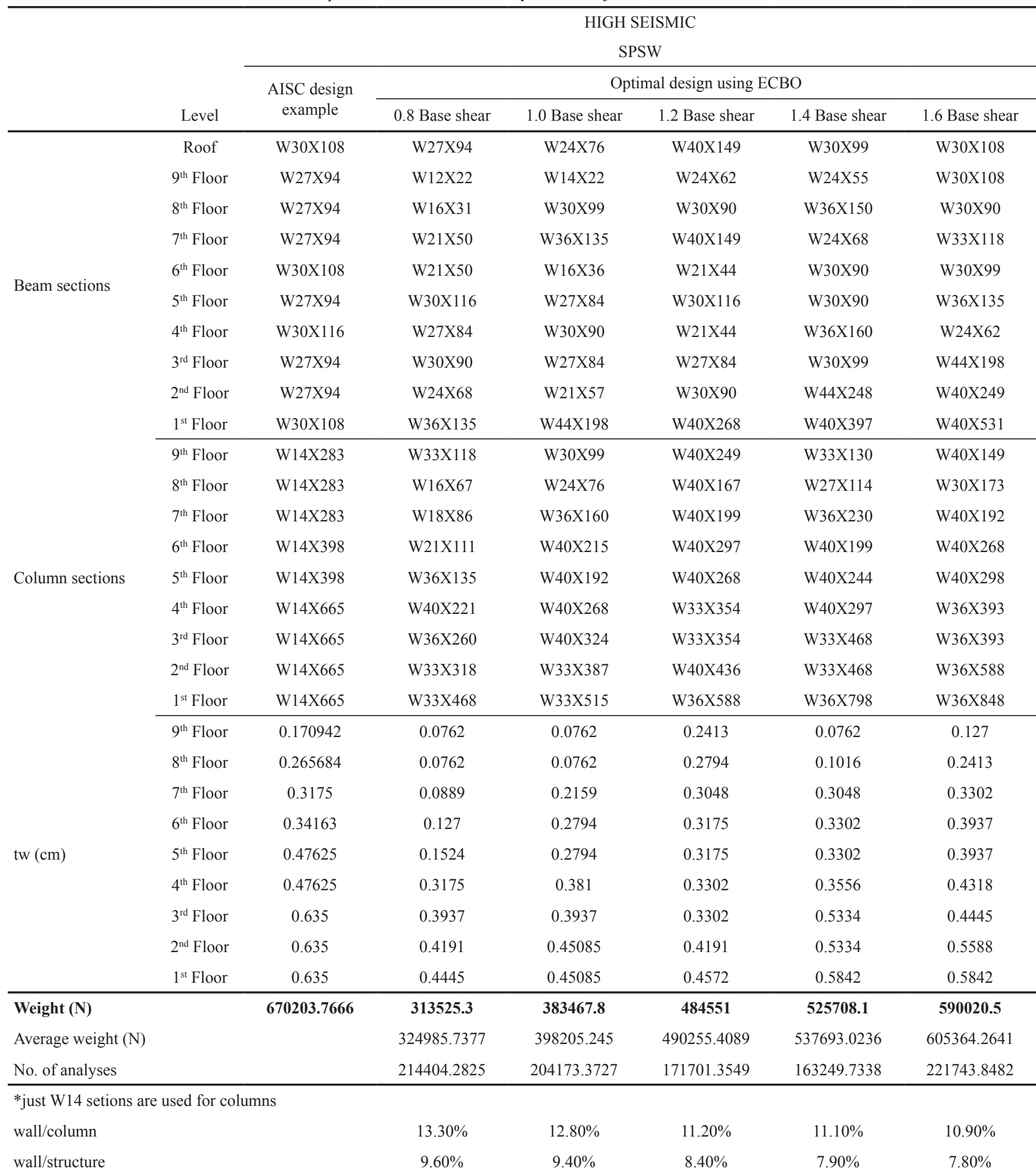

Performance based design optimization of SPSW:

In this research, uniformity of the story drifts is considered as the structural performance which is mostly based on displacement. Standard deviation of the story drifts in optimized design of the SPSW by ECBO is defined as the objective function. In this example, frame elements are those obtained in minimum weight objective optimization (third column in Table 4), and only the web plate thicknesses are the design variables with fixed cross sections for beams and columns. The story drifts of the 9-story SPSW system obtained by linear static analysis are shown in Fig. 14 for before and after the performance optimization. 
Convergence history of 9 story SPSW subjected to different base shears

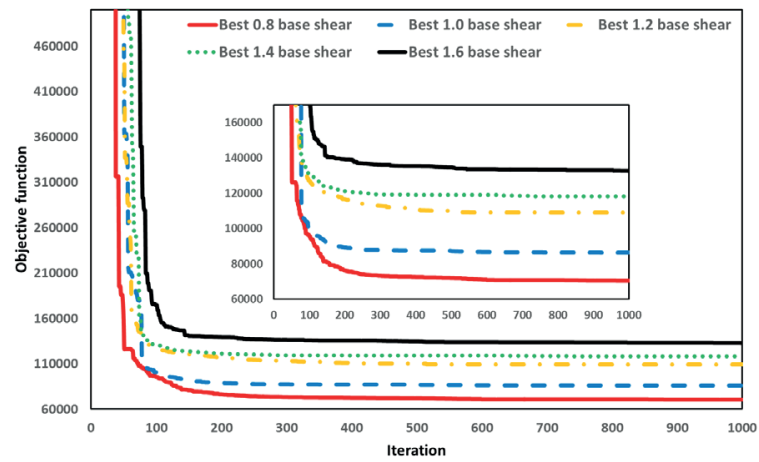

Fig. 15 Convergence curves of the 9-story SPSW subjected to different base shears

Optimal design of 9-story SPSW Base shear $=3896 \mathrm{kN}$

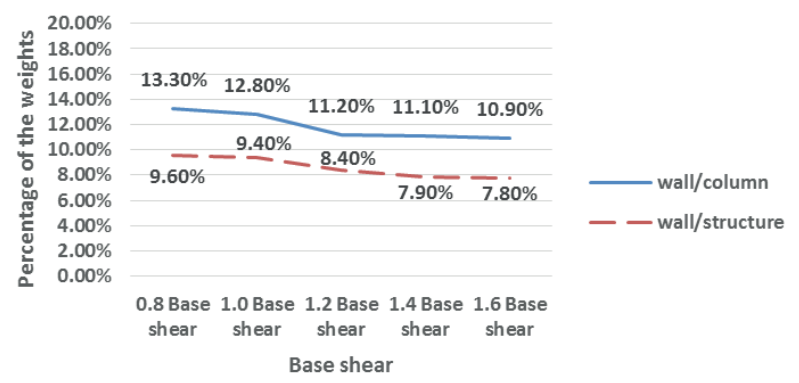

Fig. 16 Weight ratio comparison among optimal answers for different base shears

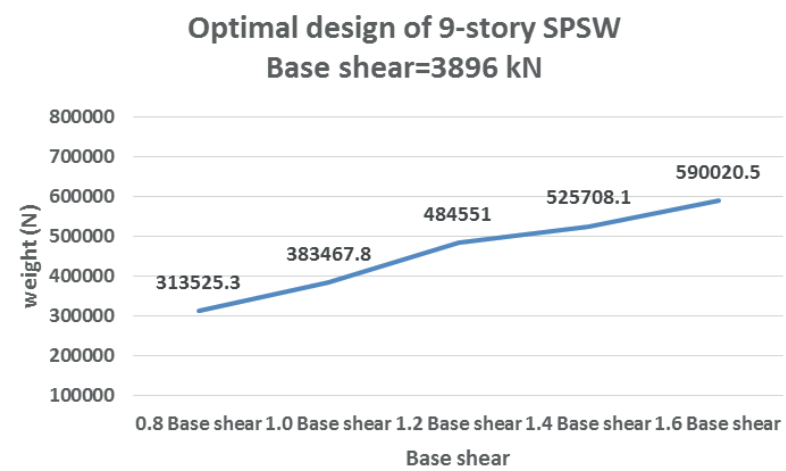

Fig. 17 Weight comparison among optimal answers for different base shears

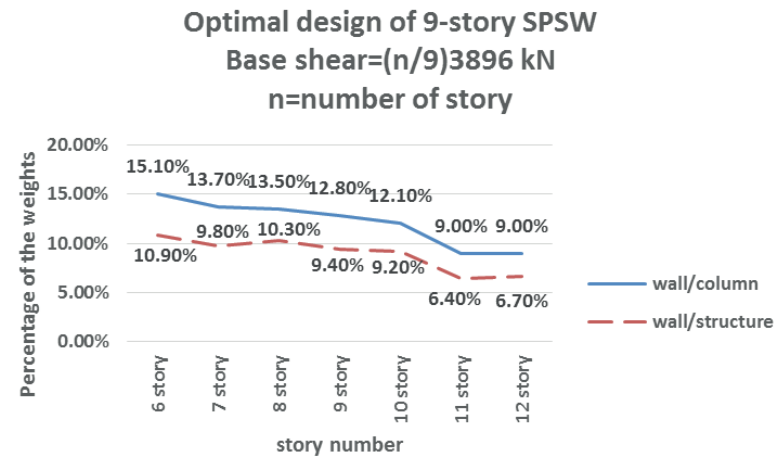

Fig. 18 Weight ratio comparison among optimal answers for different base shears

\section{Sensitivity Analysis of the Base Shear:}

Optimization of the SPSW design subjected to the five base shear $-0.8,1,1.2,1.4$, and 1.6 times value of the calculated base shear - is one of this section objective and Fig. 15 and Table 5 provide the convergence histories and comparative results of the 9 story SPSW for different base shears, respectively. Moreover, consumption of the building material in different structural elements in optimum design needs significant heed which is done in this work by sensitivity analysis of the base shear. In this regard, the amount of consumed material in columns and web plates which are resisting elements against seismic lateral loads are demonstrated in Fig. 16 in optimized mode. It can be seen that the percentage of the wall usage in different base shears is almost fixed and near 8 or 9 percent of the structure, and the little decline of the wall usage with base shear increase can be explained; this may happen because boundary elements would leave their elastic range if thicker plates were employed - as a consequence of the web plate yielding forces exerted on boundary elements. According to Fig. 17, Total weight of the frame for SPSW system increases very close to a low slope linear line with increment of the base shear. In comparison between SPW and moment frame, it is asserted that steel shear wall system has a lighter optimum structure; in like manner, it is predicted that increase of the structural weight versus augmentation of the base shear would be a line with an exponential slope, if other conventional lateral load resisting systems like moment frames and braced frames were applied. However, accreditation of these kind of results can be a good basis for future research.

\section{Optimum design of 6- to 12-story SPSW:}

In this part, seven SPSW system, or more specifically, $6,7,8,9,10,11$, and 12-story SPSW systems are studied in their optimum design form in order to investigate the steel plate performance with change of the structural height, or story. It is assumed that the base shears of the frames are directly proportional to number of the stories. Thus, the amount of base shear for n-story SPSW is taken as $n / 9$ times calculated the base shear for 9-story SPSW (=876 kips or $3896 \mathrm{kN}$ ) and is distributed vertically based on Eqs. (41) and (42) and Table 6 determines their comparative results. Fig. 18 shows that the percentage of the wall usage in SPSW system versus the story number increment declines from about $12 \%$ to $6 \%$; this decline of the wall usage may be owing to substantial web plate yielding forces exerted on boundary elements if thicker plates were used, and it may be because of the heavier column that is required in lower stories of the higher SPSWs due to the marked 
Table 6 Comparative results of the 6- to 12-story SPSW

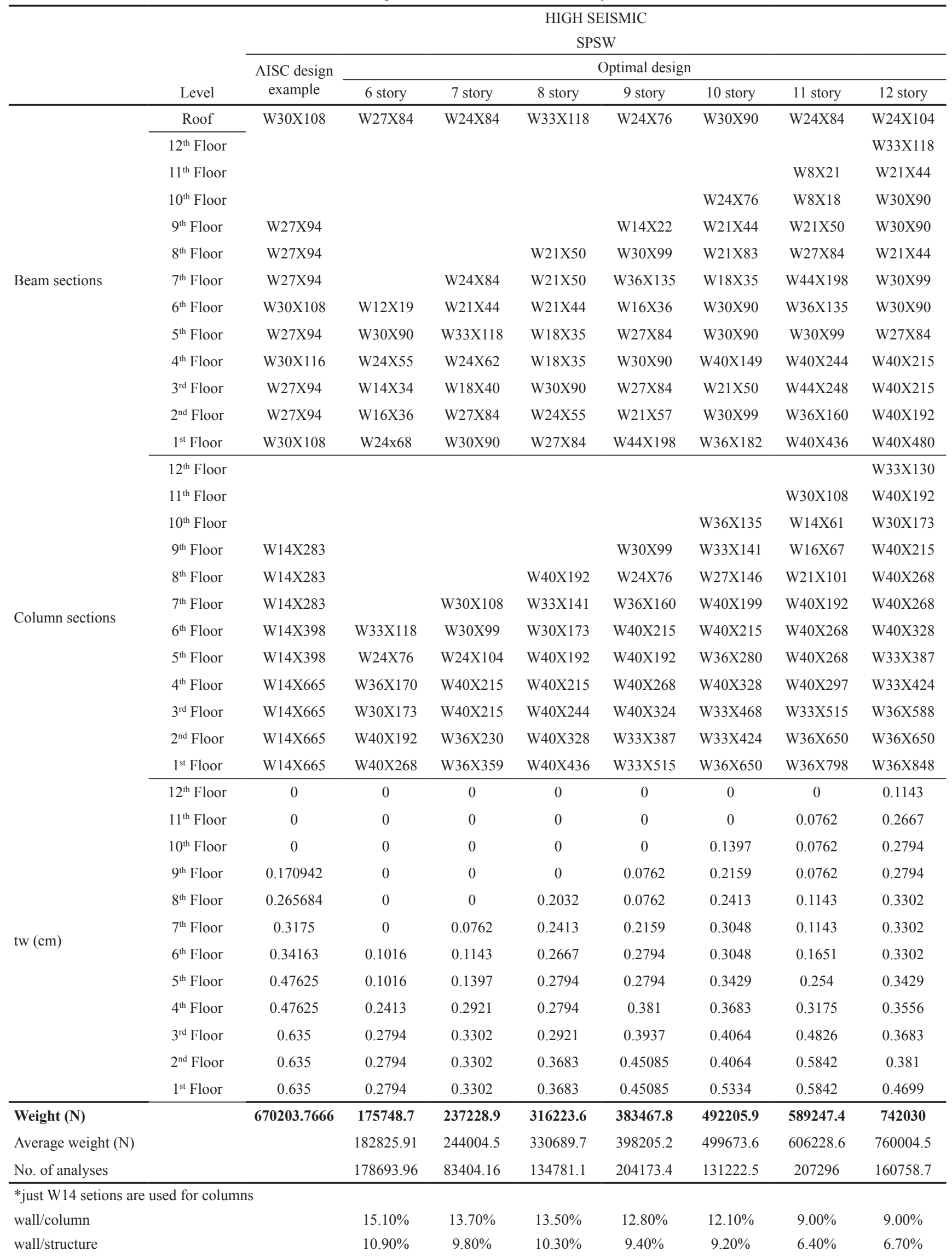




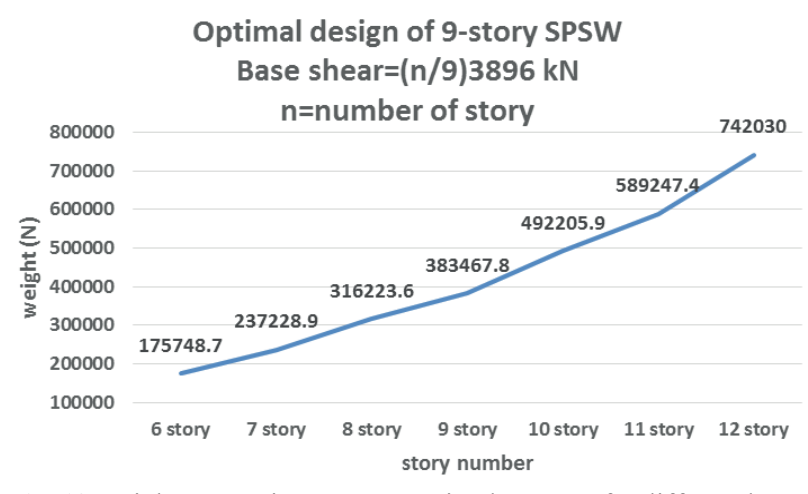

Fig. 19 Weight comparison among optimal answers for different base shears
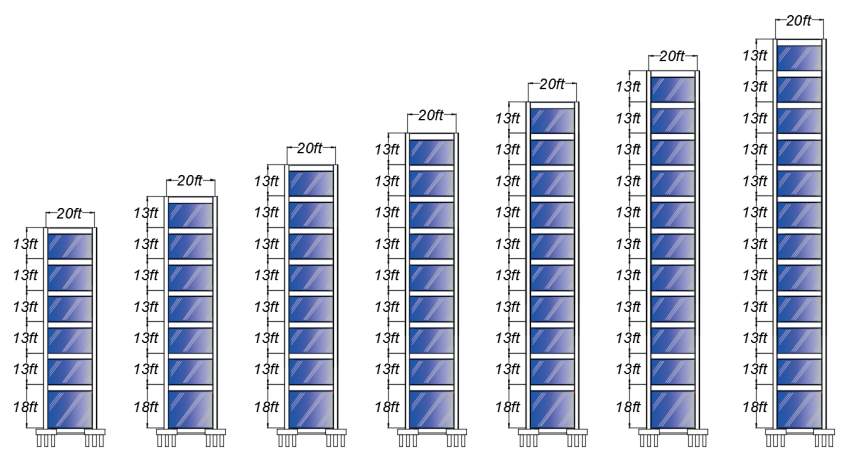

Fig. 20 Schematic of 6- to 12-story SPSWs

increase in axial load. According Fig. 19, total weight of the frame for SPSW system increases near an exponential line with increment of the story number. It is expected that drastic changes in total weight of the building in optimum design would happen if other conventional lateral load resisting systems like moment frames and braced frames were considered. Fig. 20 demonstrates the 6, 7, 8, 9, 10, 11, and 12-story SPSW systems.

\section{Conclusions}

In this study, seismic design optimization of the steel plate shear wall is performed by metaheuristic algorithms. Weight of the structure is defined as its cost in each example and minimizing the weight of the structures and enhancing performance of them are the objective functions of the problems. The most imperative conclusions can be summarized as follows:

- The excellent performance of the ECBO algorithm is demonstrated in all optimum design examples of steel plate shear wall system.

- Acceptable performance of the CBO algorithm in seismic optimum design of steel plate shear wall system since there are no complicated parameters to tune this algorithm for such sophisticated problems with complex constraints.
- Weak performance of the PSO algorithm that shows new improved PSO algorithms, such as DPSO (proposed by Kaveh and Zolghadr [26]), or and Shi et al. [27]) can be better substitutes for the standard PSO (originally proposed by Eberhart and Kennedy [28].

- High ability of the steel plate shear walls in resisting lateral loads with their diagonal tension field feature, even in their minimum weight form which is also recommended by AISC design guide number 20, implies that designers should avoid over designing the thicknesses of the steel plates for each panel.

- Domination of the uniform yielding mechanism in optimum design of steel plate shear walls is obtained by metaheuristic algorithms, which is conceived from meeting the Strong-Column Weak-Beam constraint in a decisive manner.

- Having less weight in optimum design form in comparison with other lateral load resisting system (moment frame), steel plate shear wall illustrate its superiority over other lateral load resisting systems.

- Performance based optimized design of SPSW demonstrates the fact that thicker web plates are required in top panels of the frame if the minimum weight and drift uniformity objective functions are defined separately

- Sensitivity analysis of the base shear for 9-story SPSW shows that the percentage of the wall usage is almost constant for different base shears in this particular example

- Although wall to column weight percentage decreases with increment of number of the story in SPSW system for optimum form, making use of web plates with least possible thicknesses is still vital for high performance of the system subjected to seismic loads

\section{References}

[1] Verma, G. K., Maru, S. "Some studies on behavior of steel plate shear wall in earthquake prone area: A review", International Journal of Engineering, TRENDS Technology, 4(5), pp. 1392-1397, 2013. Available at http://www.ijettjournal.org/volume-4/issue-5/ IJETT-V4I5P15.pdf [Accessed: 19.04.2018]

[2] Sabelli, R., Bruneau, M. "Design guide 20: steel plate shear walls", American Institute of Steel Construction, Chicago, IL, USA, 2007.

[3] Thorburn, J., Kulak, G. L., Montgomery, C. J. "Analysis of steel plate shear walls", Structural Engineering Report, 107., Depertment of Civil Engineering, The University of Alberta, Edmonton, Alberta, Canada, 1983. Available at https://era.library.ualberta.ca/ files/0g354f299SER107.pdf [Accessed: 19.04.2018] 
[4] Timler, P. A., Kulak, G. L. "Experimental study of steel plate shear walls", Structural Engineering Report, 114., Depertment of Civil Engineering, The University of Alberta, Edmonton, Alberta, Canada, 1983. pp. 79-87. Available at https://era.library.ualberta.ca/files/ k930bz397/SER114.pdf [Accessed: 19.04.2018]

[5] Sánchez-Olivares, G., Espín, A. T. "Design of planar semi-rigid steel frames using genetic algorithms and Component Method", Journal of Constructional Steel Research, 88, pp. 267-278. 2013. https://doi.org/10.1016/j.jcsr.2013.05.023

[6] Armand, J. L. "Minimum-mass design of a plate-like structure for specified fundamental frequency", AIAA Journal, 9(9), pp. 17391745, 1971. https://doi.org/10.2514/3.6424

[7] An, H., Huang, H. "Topology and sizing optimization for frame structures with a two-level approximation method", AIAA Journal, 55(3), pp. 1044-1057, 2017.

https://doi.org/10.2514/1.J055020

[8] Suleman, A., Sedaghati, R. "Design Optimization Against Instability of Frame Structures Undergoing Large Deflections", In: 9th AIAA/ ISSMO Symposium on Multidisciplinary Analysis and Optimization, Multidisciplinary Analysis Optimization Conferences, Atlanta, Georgia, USA, 2002, p. 5527.

https://doi.org/10.2514/6.2002-5527

[9] Kogiso, N., Mogami, K., Nishiwaki, S., Izui, K., Yoshimura, M. "Reliability-based topology optimization of frame structure with multiple modes", In: 47th AIAA/ASME/ASCE/AHS/ASC Structures, Structural Dynamics, and Materials Conference, Structures, Structural Dynamics, and Materials and Co-located Conferences, Newport, Rhode Island, USA, 2006, p. 12. https://doi.org/10.2514/6.2006-2002

[10] Missoum, S., Gurdal, Z. "A displacement based optimization for nonlinear frame structures". In: 19th AIAA Applied Aerodynamics Conference, Fluid Dynamics and Co-located Conferences, Anaheim, California, USA, 2001, p. 1553.

https://doi.org/10.2514/6.2001-1553

[11] Arora, J. S. "Methods for discrete variable structural optimization". In: Structures Congress 2000, 2000. Philadelphia, Pennsylvania, USA, May 8-10, 2002. https://doi.org/10.1061/40492(2000)23

[12] Beckers, M. "Dual methods for discrete structural optimization problems", International Journal of Numerical Methods in Engineering, 48(12), pp. 1761-1784, 2000.

https://doi.org/10.1002/1097-0207(20000830)48:12\%3C1761::AIDNME963\%3E3.0.CO;2-R

[13] Blachowski, B., Gutkowski, W. "A hybrid continuous-discrete approach to large discrete structural optimization problems", Structural Multidisciplinary Optimization, 41(6), pp. 965-977, 2010.

https://doi.org/10.1007/s00158-009-0466-1

[14] Kaveh, A., Zakian, P. "Optimal design of steel frames under seismic loading using two meta-heuristic algorithms", Journal of Constructional Steel Research, 82, pp. 111-130, 2013. https://doi.org/10.1016/j.jcsr.2012.12.003

[15] Kaveh, A., Ghafari, M. H., Gholipour, Y. "Optimum seismic design of steel frames considering the connection types", Journal of Constructional Steel Research, 130, pp. 79-87, 2017.

https://doi.org/10.1016/j.jcsr.2016.12.002
[16] Kaveh, A. "Advances in Metaheuristic Algorithms for Optimal Design of Structures", 2nd ed., Springer International Publishing, Basel, Switzerland, 2017.

https://doi.org/10.1007/978-3-319-46173-1

[17] Topkaya, C., Atasoy, M. "Lateral stiffness of steel plate shear wall systems", Thin-walled Structures, 47(8-9), pp. 827-835, 2009. https://doi.org/10.1016/j.tws.2009.03.006

[18] Rezai, M., Ventura, C. E., Prion, H. "Simplified and detailed finite element models of steel plate shear walls", In: 13th World Conference on Earthquake Engineering, Vancouver, B. C., Canada, 2004, p. 13. http://www.iitk.ac.in/nicee/wcee/article/13_2804.pdf

[19] Shishkin, J. J., Driver, R. G., Grondin, G. Y. "Analysis of steel plate shear walls using the modified strip model", Journal of Structural Engineering, ASCE, 135(11), pp. 1357-1366, 2005. https://doi.org/10.1061/(ASCE)ST.1943-541X.0000066

[20] Elgaaly, M., Caccese, V., Du, C. "Postbuckling behavior of steel-plate shear walls under cyclic loads", Journal of Structural Engineering, ASCE, 119(2), pp. 588-605, 1993. https://doi.org/10.1061/(ASCE)0733-9445(1993)119:2(588)

[21] ANSI/AISC "360-10. Specification for Structural Steel Buildings", American Institute of Steel Construction, Chicago-Illinois, USA. 2010. Available at https://www.aisc.org/publications/steel-standards/ [Accessed: 19.04.2018]

[22] ANSI/AISC "341-16. Seismic Provisions for Structural Steel Buildings", American Institute of Steel Construction, ChicagoIllinois, USA, 2016. Available at https://www.aisc.org/publications/ steel-standards/ [Accessed: 19.04.2018]

[23] Minimum Design Loads for Buildings and Other Structures (7-10). 2nd ed., American Society of Civil Engineers, Reston, Virginia, USA, 2010.

[24] Kaveh, A., Mahdavi, V. R. "Colliding bodies optimization: a novel meta-heuristic method", Computers and Structures, 139, pp. 18-27, 2014.

https://doi.org/10.1016/j.compstruc.2014.04.005

[25] Kaveh, A., Ilchi, Ghazaan, M. "Enhanced colliding bodies optimization for design problems with continuous and discrete variables", Advances in Engineering Software, 77, pp. 66-75, 2014. https://doi.org/10.1016/j.advengsoft.2014.08.003

[26] Kaveh, A., Zolghadr, A. "Democratic PSO for truss layout and size optimization with frequency constraints", Computers \& Structures, 130, pp. 10-21, 2014. https://doi.org/10.1016/j.compstruc.2013.09.002

[27] Shi, Y., Eberhart, R. C. "Parameter selection in particles warm optimization". In: International Conference on Evolutionary Programming, VII., Berlin, Germany, 1998, pp. 591-600. https://doi.org/10.1007/BFb0040810

[28] Eberhart, R., Kennedy, J. "A new optimizer using particle swarm theory". In: MHS'95., Proceedings of the Sixth International Symposium in Micro Machanic Human Science, Nagoya, Japan, 1995, pp. 39-43. https://doi.org/10.1109/MHS.1995.494215 